\title{
Hurricane Initiation: An Hypothesis
}

\author{
Kern E. Kenyon \\ 4632 North Lane, Del Mar, USA \\ Email: kernken@aol.com
}

Received 16 January 2014; revised 16 February 2014; accepted 23 February 2014

Copyright (C) 2014 by author and Scientific Research Publishing Inc.

This work is licensed under the Creative Commons Attribution International License (CC BY). http://creativecommons.org/licenses/by/4.0/

(c) (i) Open Access

\begin{abstract}
A hurricane initiation mechanism, believed to be new, is proposed for the eastern tropical North Atlantic Ocean. It starts with an outbreak of warm dry air from the Sahara Desert moving out over a fairly large region of ocean just west of the big bulge of Africa. Critical to the hypothesis is the experimental fact that heat diffuses significantly slower in air than water vapor does. In summer and early fall the desert air of the outbreak is warmer than the ocean surface it first encounters. Thus this air layer is cooled from below, which is initially stabilizing. However, water vapor diffuses up into the dry air faster than the air's heat diffuses down to the sea surface, all over the generating region simultaneously. Consequently, a horizontally large layer of air somewhat above the sea surface becomes buoyant (less dense) and rises up as a unit, and the pressure of this layer decreases by the perfect gas law. Then the water vapor in the ascending air condenses around dust particles brought in from the desert, releasing heat and producing an additional upward acceleration of the already ascending air. Atmospheric pressure lowers further in accordance with Bernoulli's law: where the (vertical) speed is greatest, the pressure is least. Measurements are suggested to validate the hypothesis if they do not already exist.
\end{abstract}

\section{Keywords}

Hurricane Initiation

\section{Introduction}

Meteorological texts do not agree on the number of conditions required to be satisfied for hurricane formation to occur: the range is from two to seven conditions ([1]-[4]). What is agreed upon is that the trigger mechanism has not yet been identified. A trigger method is offered below.

Sea surface temperatures that are warmer than a certain high value, such as $26^{\circ} \mathrm{C}$, are said, in all of the references cited above, to be necessary for hurricane generation. However, it is never fully explained how heating of the air from below can lead to low pressure in a hurricane.

In a later paper [5], an hypothesis was given for the creation of the permanent North Pacific High that begins 
with heating of the air from below. Some heat escapes from a very broad warm surface current flowing northeast off the coast of California at all times of the year. Then thermal convection in the air brings down to the sea surface air of low relative humidity, as has been observed sitting on top of the current. If temperature is not an important issue, low relative humidity implies high density and thus high pressure. So how does one get low pressure started in a hurricane by heating from below?

What is described next is a possible trigger mechanism for hurricanes. I have not been able to find all aspects of this particular suggestion anywhere in the literature. New here to the explanation is the incorporation of the double diffusion process in the atmosphere: heat diffuses significantly slower in air than water vapor does. This has been determined experimentally by laboratory measurements of the two diffusion coefficients [6]. In view of the importance of the subject, brought into focus by the potentially destructive power of the hurricane, no stone should be left unturned in the effort to understand hurricane generation.

Although the most recent meteorology texts ([7]-[9]) have enhanced our comprehension of hurricane genesis, there still remains room for additional thinking on the subject as well as for more observational work. In particular, the double diffusion concept, considered essential here, is not mentioned in any of these references, nor the earlier ones cited above, not in the chapters on hurricanes and not anywhere else. It is interesting that the idea of double diffusion in fluids was first conceived of in the late 1850s within a meteorological context as an application to the production of high altitude cirrus clouds [10], but no other atmospheric applications in the intervening 150 years have come to my attention. What a contrast to the large amount of attention given to salt fingers in the oceanographic literature since the late 1950s!

For simplicity and clarity the discussion here will be limited to the eastern tropical North Atlantic.

\section{Hypothesis}

Suppose that the formation of a hurricane starts with the outbreak of warm dry air moving west over a sizeable patch of the eastern tropical North Atlantic Ocean just outside the Sahara Desert. Such outbreaks are known to occur occasionally and they can be monitored to some extent by satellite photography. When sufficiently strong these winds bring with them sand and dust particles. Roughly a rectangular patch of ocean is involved whose north/south scale is comparable to but somewhat smaller than the latitude band of the Sahara Desert, and the location is just west of the large bulge of Africa.

Summer and early fall desert winds, particularly during the day, will be warmer than the ocean surface waters that they first encounter. Consequently, the dry air will be cooled from below, which is initially a stabilizing situation. No thermal convection in either medium, ocean or atmosphere, is anticipated. Striking out in such a manner, which appears to be counterintuitive, is there any conceivable way by which clouds can begin to form in the dry atmosphere over this region of the ocean, as has been observed to happen from satellites?

To proceed further with the qualitative discussion, a critical fact needs to be brought in: heat diffuses significantly slower in air than water vapor does (see the experimental data located on two pages in [6]). A short chain of logic helps to explain why this turns out to be true. Since about $80 \%$ of air is made up of nitrogen molecules, heat in air diffuses mostly by the bumping of nitrogen molecules into other nitrogen molecules. The much smaller number of water vapor molecules diffuses primarily by knocking into nitrogen molecules, which are considerably heavier, and thus the water vapor molecules recoil farther and faster from the collisions than the nitrogen molecules do from colliding with each other.

Next, the water vapor from the sea surface will diffuse upward into the warm dry air faster than the heat of the air will diffuse down to the sea surface, over all the area of the dry air and all at the same time. Just a short distance above the sea surface, the air will become more humid while retaining its original warmth. Therefore, this layer of air will become buoyant, and will begin to rise up as one unit. Not only that, but the pressure of the layer lowers because of the increased presence of water vapor, decreased density, at nearly constant temperature, according to the perfect gas law.

During this incipient stage it is not envisioned that there be any pre-existing rotary motion in horizontal planes parallel to the sea surface, which might somehow amplify at a later stage.

Then, still in the initiation phase, consider that the outbreak of desert air has originally brought dust to the ocean's hurricane generating region, and that the water vapor that has diffused up from the sea surface begins to condense around the nuclei afforded by these particles, releasing heat to the environment. It follows that the warm dry recently humidified air, which is already ascending due to increased buoyancy, will warm up further and accelerate upward faster. Consequently, the air pressure will become substantially lower than before in ac- 
cordance with Bernoulli's law: the pressure is least where the (vertical) speed is greatest.

By means of the two-steps consecutively, vertical diffusion of water vapor over a big area causing the ascent of buoyant air in one large column, followed by the condensation of water vapor accompanied by enhanced vertical acceleration, the probability is much reduced that the return flow of air to the sea surface will take place anywhere nearby the rising column.

\section{Discussion}

Although the above hypothesis is of a qualitative nature, certain specific measurements, if they do not already exist, would be helpful for evaluating its truthfulness. Among them are sea surface temperature, air temperature, and relative humidity near the sea surface and at selected heights above the surface. Horizontal wind speed is important because, although evaporation increases with increasing wind speed, too high a speed accompanied by turbulence, may interfere with the vertical diffusion of water vapor. If possible some measure of dust particle size and concentration would be nice to have as well (too much dust apparently inhibits hurricane growth [7]).

Such observations do not need to be made routinely everywhere but rather following each outbreak of desert air from Africa and just within the generation region. Not every outbreak is expected to lead to the formation of a hurricane, but the probability of occurrence is not known at this point. Since the Canary Islands, and possibly some other islands, lie at the far eastern boundary of the hurricane breeding grounds, they may prove to be convenient fixed platforms for obtaining many of these suggested measurements. Otherwise, buoys, robots, planes and ships might be necessary even though expensive (especially the ships). Satellites are useful for spotting potential hurricane generation locations but they are unable to supply the much needed ground (or air) truth.

In the whole discussion above it was more or less assumed that warm dry air from the Sahara Desert would often end up laying directly over the sea surface. However, if between the desert air and the sea surface there is a layer of cool moist air (marine layer [11]), and the two layer air system is gravitationally stable, there should be no change to the main argument: water vapor from the lower moist layer will diffuse up into the dry layer faster than heat will diffuse downward causing buoyancy at the bottom of the dry air layer, a lowering of the pressure, and causing ascending motion. New measurements may be needed to verify this arrangement as well.

\section{Conclusions}

A new hurricane generation method is proposed by a qualitative argument. Central to the hypothesis is the double diffusion mechanism applied to the atmosphere: heat diffuses in air significantly slower than water vapor does. The two diffusion coefficients involved have been measured in the laboratory. When summer warm and dry air from the Sahara Desert moves out over a large region of the eastern tropical North Atlantic Ocean, it is initially stabilized by being cooled from below, either directly by the sea surface or by a cool moist marine layer sandwiched between the sea surface and the warm dry desert air. Then water vapor from the sea surface or the marine layer diffuses up into the dry air faster than the dry air's heat diffuses downward. Consequently, the air at the bottom of the dry layer becomes less dense due to increased relative humidity while the temperature remains practically unchanged. Therefore, pressure lowers by the perfect gas law and the now buoyant air layer rises forming one large column.

The second step in the initiation process is that the water vapor in the already ascending air condenses around dust particles brought into the region with the desert wind. Heat is thereby released causing the rising air to accelerate faster upward. Finally, Bernoulli's law predicts a further lowering of the pressure: where the (vertical) speed is greatest, the pressure is least.

Specific observations of the ocean and atmosphere in the hurricane generation area are recommended in order to support or refute the proposed initiation hypothesis.

\section{Acknowledgements}

Comments by the reviewer strengthened the text. Douglas Kenyon and Caroline Craun improved the syntax.

\section{References}

[1] Palmen, E. and Newton, C.W. (1969) Atmospheric Circulation Systems. Academic Press, New York, 471-522.

[2] Musk, L.F. (1988) Weather Systems. Cambridge University Press, New York, 133-142. 
[3] Moran, J.M. and Morgan, J.M. (1991) Meteorology, the Atmosphere and the Science of Weather. MacMillan College Publishing Company, New York, 338-355.

[4] Anthes, R.A. (1997) Meteorology. Prentice-Hall, New Jersey, 113-124.

[5] Kenyon, K.E. (1999) North Pacific High: An Hypothesis. Atmospheric Research, 51, 15-34. http://dx.doi.org/10.1016/S0169-8095(98)00110-0

[6] Cussler, E.L. (1997) Diffusion. Cambridge University Press, Cambridge, 497.

[7] Ackerman, S.A. and Knox, J.A. (2015) Meteorology: Understanding the Atmosphere. 4th Edition, Jones \& Bartlett Learning, Burlington, 244-271.

[8] Krishnamurti, T.N., Stefanova, L. and Mirsa, V. (2013) Tropical Meteorology. Springer Atmospheric Sciences, New York, 331-359. http://dx.doi.org/10.1007/978-1-4614-7409-8_16

[9] Ahrens, C.D. (2013) Meteorology Today. 10th Edition, Brooks/Cole, Belmont, 424-455.

[10] Jevons, W.S. (1857) On the Cirrus Form of Clouds. The London, Edinburg and Dublin Philosophical Magazine, 4th Series, 14, 22-35.

[11] Moran, J.M. (212) Weather Studies: Introduction to Atmospheric Science. American Meteorological Society, Boston, 412. 